\title{
Primary giant cell malignant fibrous histiocytoma-associated with renal calculus
}

\author{
Adem Altunkol, MD; ${ }^{*}$ Murat Savas, MD; ${ }^{\dagger}$ Halil Ciftci, MD; ${ }^{\dagger}$ Mehmet Gulum, MD; ${ }^{\dagger}$ Ismail Yagmur, MD; ${ }^{\dagger}$ \\ Muharrem Bitiren, $M D^{\S}$
}

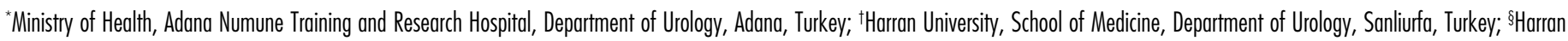
University, School of Medicine, Department of Pathology, Sanliurfa, Turkey

Cite as: Can Urol Assoc J 2014;8(3-4):e193-5. http://dx.doi.org/10.5489/cuaj.1485 Published online March 11, 2014.

\section{Abstract}

Malignant fibrous histiocytomas (MFH) are the most commonly seen soft tissue sarcomas in adults. It is rarely seen in some visceral organs. Kidneys are the parenchymal organs in which MFHs are most frequently seen. More than 50 cases of primary renal MFH have been reported. Among these cases, only 1 was reported as primary giant cell subtype in association with urolithiasis. This case report is the second such case with the these characteristics.

\section{Introduction}

The primary malignant fibrous histiocytomas (MFH) of the kidney are rarely seen malignant neoplasms of the kidney. ${ }^{1}$ Primary malignant mesenchymal tumours of the kidney constitute $1 \%$ to $3 \%$ of the malignant tumours of the kidney and primary malignant fibrous histiocytomas constitute $6 \%$ of the primary renal sarcomas. ${ }^{1,2}$ MFHs are the most frequently seen type of sarcoma in adults. MFHs cause local mass formation in the subcutaneous or deep soft tissues of the extremities, trunk and retroperitoneal region, in order of frequency. ${ }^{3,4}$ Some cases in the kidneys, prostate, urinary bladder, spermatic cord, liver, pancreas, thyroid and breast were rarely reported. ${ }^{2,5-11}$ There are 4 defined histomorphological patterns of MFH: (1) storiform-pleomorphic subtype, (2) myxoid subtype, (3) giant cell subtype and (4) inflammatory subtype (in order of frequency). Giant cell subtypes are lesions consisting of widespread hemorrhagic and necrotic areas histologically characterized by numerous multinuclear osteoclast-type giant cells. The terms of malignant giant cell tumours of soft tissues, giant cell sarcoma, giant cell undifferentiated pleomorphic sarcoma and malignant osteoclastoma are synonyms used for this variant. ${ }^{3,4}$

Our case report is a giant cell subtype of MFH accompanied by renal stones. In the literature review, only 1 case with the same characteristics was reported. ${ }^{12}$ Our case is the second.

\section{Case report}

A 63-year-old male patient was referred to our urology department with complaints of weight loss $(15 \mathrm{~kg}$ in last 3 months), bilateral blunt flank pain and intermittent macroscopic hematuria. Upon physical examination, we found a mass involving the right hypochondriac, lumbar areas and certain parts of the umbilical area on palpation. Laboratory analysis revealed hemoglobin as $7.8 \mathrm{~g} / \mathrm{dL}$, hematocrit as $27 \%$ and leucocyte count as $17200 \mu \mathrm{L}$.

The ultrasonography revealed that the right kidney was $212 \times 80 \mathrm{~mm}$ in size and was heterogeneous. We also detected a stone, $25 \mathrm{~mm}$ in diameter, forming an echogenic area at the ureteropelvic junction causing grade 3 pelvicaliceal dilatation in the right kidney. Also detected was debris material in the pelvicaliceal system of kidney, compatible with pyonephrosis and a mass lesion in the kidney consisting of cystic regions. No renal function was detected in the right kidney during intravenous urography (IVP) (Fig. 1, part A). A severe increase in the size of the right kidney, grade 3 dilatation and a cystic solid mass compatible with pyonephrosis in pelvicaliceal structures and 2 stones of $2.5 \mathrm{~cm}$ and $0.6 \mathrm{~cm}$ in diameter in the right upper pole were detected in abdominal computerized tomography $(\mathrm{CT})$. An increase in density of perirenal fat tissue and thickening in the Gerota's fascia was seen (Fig. 1, part B). Bilateral pleural fluid and 2 probable metastatic nodules in soft tissue density with diameters of $1 \mathrm{~cm}$ and $1.5 \mathrm{~cm}$ were detected in the superior segment of the lower lobe of the right lung during CT of the thorax. The patient had a renal stone accompanied by a malignant renal mass, and a right radical nephrectomy was performed.

Macroscopic nephrectomy material of $950 \mathrm{~g}$ in weight, $22 \times 15 \times 12 \mathrm{~cm}$ in size with a ureter of $5 \mathrm{~cm}$ in length was detected. It was seen that the renal capsule was ruptured and the necrotic tumour tissue, which was gray-yellow in colour, had protruded outside the capsule (Fig. 1, part C). It 
was observed in the sections that the normal anatomy of kidney could not be distinguished; there were patchy areas of necrosis and hemorrhage, which were dirty yellow in colour, and the pelvicaliceal structures were irregular and dilated (Fig.1, part D). Two gray-white stones of $2.5 \mathrm{~cm}$ and $0.6 \mathrm{~cm}$ in diameter were found in the upper pole. Additionally, gray-yellow tissue with of a volume of $100 \mathrm{cc}$ recorded as Gerota's fascia was detected.

It was observed in the microscopic examination that the neoplastic tissue was composed of pleomorphic cells with ovoid-spindle shaped nuclei, pleomorphic polygonal cells with apparent nucleoli, and numerous multinuclear giant cells (Figure 1, part E). Over 10 mitotic activities in neoplastic cells, in both typical and atypical mitosis, were detected in 10x magnification. Tumour invasion was detected in perirenal fat tissue and Gerota's fascia. About half of the tumour areas were necrotic. The giant cells and pleomorphic polygonal cells were dyed as vimentin positive in immunohistochemical dye CD68 (Fig. 1, part F). Both cell types were dyed negative in epithelial membrane antigen, pancytokeratin, actin and desmin. The remaining kidney tissue was non-specific chronic inflammation. Considering these findings, this case was defined as giant cell MFH. The histological stage of the tumour was stage 3 and the grade was $\mathrm{pT} 2 \mathrm{~b}, \mathrm{pNx}, \mathrm{pMx}$, according to the 2010 version of American Joint Committee on Cancer (AJCC) staging system.

Additional radiotherapy and chemotherapy were planned. However, the patient died due to a massive heart attack 1 month after surgical treatment without adjuvant therapy.

\section{Discussion}

MFHs are the most commonly seen sarcomas in adults; most occur in patients in their sixth or seventh decade of life. ${ }^{3,7}$ Today it is reported that the cells that MFHs originate from fibroblasts or undifferentiated mesenchymal cells; the available histiocytes are reactive and using the term fibrohistiocytic would be definitive as well. ${ }^{3}$ It is suggested that primary renal MFHs might originate from renal capsule cells or undifferentiated primitive cells. ${ }^{1}$

These are tumours causing masses that grow rapidly generally in a few months. They form a renal mass generally invasive in the renal parenchyma and perinephritic tissues, which are clinically painful, firm in consistency and necrotic. ${ }^{1,12} \mathrm{MFHs}$, which are retroperitoneal in origin, cause rapid weight loss. ${ }^{6}$ Our patient was 63 , with a $15-\mathrm{kg}$ weight loss in 3 months; she also had a large, necrotic and palpable mass, with a total loss of renal parenchyma and ruptured capsule in wide regions.

No data except renal mass could be obtained with preoperative screening methods. ${ }^{5,13}$ Therefore, the diagnosis of MFH can be made by histopathological evaluation and immunohistochemical cellular assay. Morphologically, the tumour pattern, as seen in other subtypes, is composed of a mixture of fibroblasts, histiocytes and osteoclast-type giant cells in relatively changing amounts. The fibroblasts show pleomorphism, and apparent mitotic activity and a positive immunoreactivity with vimentin are seen. The giant cells name the tumour and their histological origins are shown with panhistiocytic markers, such as Leu-M3 and CD68. ${ }^{6,14}$ Hemorrhage, cystic areas and necrosis are diffuse in tumours. Focal chondroid, osteoid or mature bone formation may be present. ${ }^{1,3,15}$

The primary differential diagnosis of primary giant cell subtype of MFH should be made with rarely seen osteoclastic giant cell leiomyosarcoma of kidney and osteoclastoma-like undifferentiated carcinoma or undifferentiated carcinoma rich in giant cells. In the osteoclastic giant cell leiomyosarcoma of kidney, you should have positive immunoreactivity with smooth muscle actin, desmin and pancytokeratin. In osteoclastoma-like undifferentiated carcinoma or undifferentiated carcinoma rich in giant cells, you should have positive immunoreactivity with pancytokeratin without positive immunoreactivity with histiocytic markers - these allow for a differential diagnosis. ${ }^{1,3}$ In our case, the diagnosis and the differential diagnosis were made with immunohistochemically positive immunoreactivity with CD68.

MFHs are high-grade pleomorphic sarcomas found in adults. ${ }^{3}$ The primary renal MFHs are biologically aggressive and poor prognostic malignant neoplasms. Radical nephrectomy is preferred. No defined chemotherapy combinations are present. The evaluations of chemotherapy and radiotherapy are limited due to the small number of case reports. ${ }^{1,5,13,14,16}$ In the literature review, chemotherapy regimens of cyclophosphamide, vincristine, adriamycin and actinomycin-D combinations, doxorubicin andiphosphamide are present. ${ }^{1,13}$ Local recurrence occurs in more than $50 \%$ of patients a few months after surgery. ${ }^{14}$ The expected recurrence time after adjuvant chemotherapy is reported as 12 months, 17 months and 28 months. ${ }^{1,2,13}$ Lung and bone metastasis are quite frequent and the 5 -year survival rate decreases to $34 \%$ in this case. ${ }^{6}$ In the current case, Gerota's fascia invasion and metastatic focus in the lung were present and the patient died 1 month after surgery.

In patients with signs and symptoms of classical nephrolithiasis, the malignant masses of kidneys can easily be overlooked. Although the relationship between urolithiasis and squamous carcinomas of renal pelvis is well-known, no etiopathological relationship between urolithiasis and renal malignant mesenchymal tumours has been found and this rare association is accidental. ${ }^{1}$

\section{Conclusion}

When a kidney stone is encountered, one should keep in mind that the disease accompanying the stone may be MFH, 


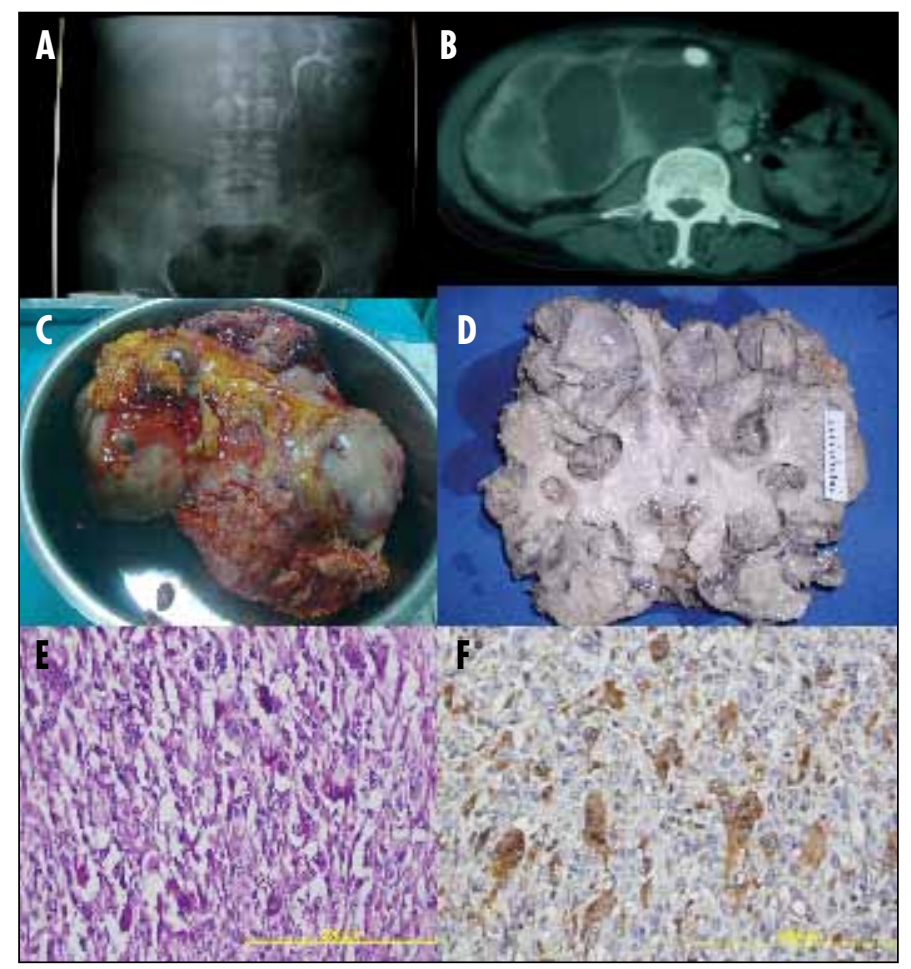

Fig. 1. A: Right kidney without renal function on intravenous urography. B: Increase in the size of the right kidney, pelvicaliceal dilatation, cystic solid mass, 2 stones in right upper pole, increased perirenal fat tissue density, thickening of Gerota's fascia. C: Necrotic tumour rupturing renal capsule. D: Nodular structures dirty yellow in colour, tumour tissue with necrotic areas and apparent dilatation of pelvicaliceal structures changing normal renal anatomy. E: Neoplastic tissue consisting of pleomorphic polygonal cells with spindle-shaped nuclei and apparent nucleoli and reactive multinuclear giant cells (hematoxylin and eosin stain, original magnification $\times 400$ ). F: Immunohistochemically positive immunoreactivity with histiocyte marker CD68 in multinuclear giant cells (immunostains, original magnification $\times 400$ ).

even though it is extremely rare. It should not always be associated with the disease, but the presence of the stone must never eliminate MFH as a potential diagnosis. In addition, the rapid weight loss seen in our case should serve as a warning about the malignancies accompanying renal stones.

Competıng interests: Dr. Altunkol, Dr. Savas, Dr. Ciftci, Dr. Gulum, Dr. Yagmur and Dr. Bitiren all declare no competing financial or personal interests.
This paper has been peer-reviewed.

\section{References}

1. Takahashi S, Tsukamoto T, Lieber M. Genitourinary sarcomas in adults. In: Vogelzang NJ eds. Comprehensive textbook of oncology. St. Louis, Williams and Wilkins, 1992;1124-39.

2. Muretto $P$, Lemma $E$, Grianti $C$, et al. Inflammatory malignant fibrous histiocytoma of the kidney: An immunohistochemical and ultrastructural study. Tumori 1985;71:147-53.

3. Weiss SW, Goldblum JR. Malignant fibrohistiocytic tumors. In: Weiss SW, editors. Enzinger and Weiss's soft tissue tumors. 4th ed. St Louis: Mosby, 2002;491-535.

4. Alguacil-Garcia A, Unni KK, Goellner JR. Malignant giant cell tumor of soft parts: ultrastructural study of four cases. Cancer 1977;40:244-53. http://dx.doi.org/10.1002/1097-0142(197707)40:1<244::AlDCNCR2820400137>3.0.C0;2-\#

5. Farrow GM, Harrison EG Jr, Utz DC. Sarcomas and sarcomatoid and mixed malign tumors of the kidney in adults. Cancer 1968;22:556-63. http://dx.doi.org/10.1002/1097-0142(196809)22:3<556::AIDCNCR2820220310>3.0.C0;2-N

6. Fletcher CDM. So-called fibrohistiocytic tumours. In: Fletcher CDM, Unni KK, Mertens F, editors. WHO classification of tumours. Pathology and genetics of tumours of soft tissue and bone. 2th ed. Lion: IARCPress, 2002;109-27.

7. Goodman AJ, Graeney MG. Malignant fibrous histiocytoma of the bladder. Br J Urol 1985;57:106-7. http://dx.doi.org/10.1111/i.1464-410X.1985.tb08996.x

8. Kumala RV, Seppanen JH, Vaajelahti PJ, et al. Malignant fibrous histiocytoma of the prostate: case report. Scand J Urol Nephrol 1994;28:429-31. http://dx.doi.org/10.3109/00365599409180527

9. Demir L, Can A, Dirican A, et al. Malignant fibrous histiocytoma of the spermatic cord in a patient with policystic kidney disease: Review of the literature. Clin Genitourin Cancer 2012;10:280-3. http://dx.doi. org/10.1016/i.lgc.2012.03.003

10. Şen Türk N, Kelten C, Özkalay Özdemir N, et al. Primary hepatic malignant fibrous histiocytoma of the kidney: report of a case. Turkish J Pathol 2010;26:165-7. http://dx.doi.org/10.5146/tipath.2010.01017

11. Yao D, Dai C. Clinical characteristics of the primary hepatic malignant fibrous histiocytoma in China: A case report and review of the literature. World I Surg Oncol 2012;10-3.

12. Chen $\mathrm{CH}$, Lee PS, Han WJ, et al. Primary giant cell malignant fibrous histiocytoma of the kidney with staghorn calculi. J Postgrad Med 2003;49:246-8.

13. Papadopoulos I, Rudolph P. Primary renal malignant fibrous histiocytoma: Case report. Urol Int 1999;63:136-8. http://dx.doi.org/10.1159/000030434

14. Froehner M, Manseck A, Haase $M$, et al. Locally recurrent malignant fibrous histiocytoma: A rare and aggressive genitourinary malignancy. Urol Int 1999;62:164-70. http://dx.doi.org/10.1159/000030383

15. Guccion $\mathrm{JG}$, Enzinger FM. Malignant giant cell tumor of soft parts: An analysis of 32 cases. Cancer 1972;29:1518-27. http://dx.doi.org/10.1002/1097-0142(197206)29:6<1518::AlDCNCR2820290616>3.0.C0;2:\#

16. Ptochos $A$, Karydas $G$, losifidis N, et al. Primary renal malignant fibrous histiocytoma. A case report and review of the literature. Urol Int 1999;63:261-4.

Correspondence: Dr. Adem Altunkol, Ministry of Health, Adana Numune Training and Research Hospital, Department of Urology, Adana, Turkey; ademaltunkol@hotmail.com 